\title{
Insecticide residues cross-contamination of oilseeds during storage (second part)
}

\author{
Sylvie DAUGUET \\ CETIOM \\ Service Transformation et valorisation des graines \\ oléagineuses, 11 rue Monge, Parc industriel, \\ 33600 Pessac \\ $<$ dauguet@cetiom.frs
}

\begin{abstract}
This article is a continuation of the article Insecticide residues cross-contamination of oilseeds during storage published in OCL vol. 14, $n^{\circ} 6$, November-December 2007. The last article presented the results obtained by an investigation on stored sunflower seeds, and this new work presents results on stored rapeseed. Pesticide residues are found in oilseeds and crude oils: they are mainly organophosphate insecticides (pirimiphos-methyl, malathion) used in empty storage facilities and for application to stored cereal grains. French regulation does not allow use of these insecticides on stored oilseeds. These residues arise from cross-contamination from storage bins and facilities, and not from illegal use. This uptake of insecticide residues from their storage environment by oilseeds can lead to levels that can exceed regulatory limits. An investigation in 13 grain storage companies allowed us to follow the course of 21 rapeseed batches, from their receipt at the storage facilities to outloading. Samples from each of these batches, made at outloading, were analysed by ITERG, looking for insecticide residues. Traceability of rapeseed established by storers allowed us to identify cross-contamination sources. Results are slightly different from those obtained the previous year on sunflower seeds. Substances discovered were mostly pirimiphos-methyl, and malathion, plus chlorpyriphos-methyl (two cases) and deltamethrin (one case). Pirimiphos-methyl was most commonly detected, and caused most cases of non-accordance with regulatory levels. Main cross-contamination hazard resulted from treatment of cereals at their receipt during the same period than rapeseed receipt, especially when these cereals treatments were frequent on that silo. Other situations led to cross-contaminations, but generally of lower levels: outloading of rapeseed after outloading of treated cereals, rapeseed stored in bin that contained previously treated cereals, empty bins and handling equipment treated before receipt of rapeseed.
\end{abstract}

Key words: rapeseed, insecticide, pesticide residues, storage, cross-contamination

2007-2008). Dichlorvos and malathion were forbidden and could be used only until $1^{\text {st }}$ December 2008. As MRL for dichlorvos lowered to $0,01 \mathrm{mg} / \mathrm{kg}$ in cereals in November 2006, this substance, which was largely used until the previous storage season 2006-2007, could not be used by storage companies anymore. MRL of malathion didn't lower in cereals, so it could be used until the last time.

So, we can hypothesise that cross-contamination phenomena can exist, between these various kinds of seeds, cereals and oilseeds, sharing the same grain handling and storage system. This phenomena has already been demonstrated in Canada on rapeseed [1-3], when empty bins are treated with organophosphorous insecticides (bromophos, malathion, fenitrothion). Canadian storers were warned that treating before storing rapeseed could lead to residues above the maximum allowable limits.

Uptake of pirimiphos-methyl by a single-layer of rapeseed or wheat on galvanized-steel surfaces was demonstrated in a laboratory study [4, 5]. It was shown that, for small bins (less than
50 tons), it could lead to residues quantities above regulatory limits.

In order to improve our knowledge about this post-harvest insecticide cross-contamination, especially in big elevators, an investigation was carried out with the collaboration of several French grain storage companies on sunflower seeds during the storage season 2006-2007 [6]. Real cases were observed, with an accurate traceability of sunflower seeds lots all along their route inside storage facilities (from receipt to outloading) to find where the insecticides were taken up by the oilseeds. This study showed that cross-contaminations of oilseed by insecticide residues really occur in storage facilities. Substances found were: pirimiphos-methyl, dichlorvos and malathion. The highest risk of contamination appears when cereals are systematically treated at outloading, just before outloading of oilseeds, using the same conveyer circuits.

Results presented in this article come from an investigation, similar to the previous one on sunflower seeds. This new investigation concerns rapeseed harvested in 2007. Dichlorvos was not used anymore during the storage 
season $2007-2008$, so grain protection strategies changed. Rapeseed is harvested in junejuly, like cereals (wheat and barley). So, we can guess that results will be different in this new investigation on rapeseed from those obtained on sunflower seeds.

\section{Materials and methods}

The process adopted for this survey on rapeseed was:

- Identifying, with storage operators, rapeseed lots that could be "traced" (recording of each step from receipt to outloading): 13 grain storage companies agreed to collaborate, and allowed us to follow 21 rapeseed bins. These companies were situated throughout the rapeseed crop area.

- Making a mean sample from each batch representative of rapeseed arriving at the storage facilities ("first sample") and preserving it. These samples are preserved if we suspect that contamination occurred before reception by the grain company.

- Making a mean sample representative of outloaded rapeseed, "final sample", when the traced lot is commercialized (from one to eight months after harvesting). All these "final samples" were analysed. In one case, we had 2 samples for one rapeseed batch (two different conveyer circuits were used), so that we analysed 22 final samples. The sampling method used was based on a standard method (moving seeds, for contaminant with heterogeneous distribution determination, PR EN ISO 24333:2006): 25 elementary samples for 500 tons evenly distributed during the outloading (one elementary sample each 20 tons). This method was usually well observed by the commercial operators.

- Filling a questionnaire called "traceability" which recorded each step from receipt to outloading. Operators had to indicate if treatments were applied on empty bins or handling equipment, or if cereals were treated at their receipt or outloading and if these cereals used the same conveyer circuit inside the storage facilities just before rapeseed, etc. - Determination of insecticide residues in all "final samples": the analytical laboratory
ITERG (Pessac, 33, France) conducted these determinations, using the "common method" developed since three years by a group of about twenty French laboratories (public and private) coordinated by CETIOM and ITERG: Soxhlet extraction of oil with hexane (NF EN ISO 659), pre-purification with acetonitril and freezing, purification with cartridge C18 and cartridge Florisil, analysis by gaseous chromatography with detection NPD (organophosphorous) and ECD (pyrethrinoid).

\section{Results}

\section{Twenty-two samples were analyzed (table 1, figure 1)}

The insecticides used on cereals and for storage facilities treatment were detected: pirimiphosmethyl, malathion, chlorpyriphos-methyl and deltamethrin (only 1 case). Most commonly detected substance was pirimiphos-methyl, quantified in $55 \%$ of samples. This substance also caused most cases of non-accordance with MRL, in $32 \%$ of the samples.

On the whole, final samples were quite contaminated as half of them contained more than $34 \mu \mathrm{g} / \mathrm{kg}$ of insecticide residues (sum of resi- dues median), and $10 \%$ of them contained more than $581 \mu \mathrm{g} / \mathrm{kg}$ (sum of residues $9^{\text {th }}$ decile).

Compared with the results obtained in the previous investigation on sunflower harvested in 2006 (table 2, figure 2), pirimiphos-methyl is much more often found in rapeseed, especially above MRL, and with higher levels (mean for rapeseed $130 \mu \mathrm{g} / \mathrm{kg}$, mean for sunflower seeds $19 \mu \mathrm{g} / \mathrm{kg}$ ). Dichlorvos is not found anymore in rapeseed because of the new regulation.

\section{Analytical results for each substance (figure 3, figure 4)}

Pirimiphos-methyl - 6 samples are contaminated above $100 \mu \mathrm{g} / \mathrm{kg}$ (C17, C10, C9, C21, C23, C11), including one sample with more than $1000 \mu \mathrm{g} / \mathrm{kg}$ (C17). All the other samples have contents close to MRL $(50 \mu \mathrm{g} / \mathrm{kg})$ or below. Sample C22 contain pirimiphosmethyl residues between 50 and $100 \mu \mathrm{g} / \mathrm{kg}$, while samples $\mathrm{C} 12, \mathrm{C} 3, \mathrm{C} 8, \mathrm{C} 16$ and $\mathrm{C} 13$ have contents between 15 and $50 \mu \mathrm{g} / \mathrm{kg}$. Pirimiphos-methyl was not detected in every other sample.

Malathion - Only one sample have a high content of malathion (C21, $322 \mu \mathrm{g} / \mathrm{kg})$. One sample (C1) has a malathion content between

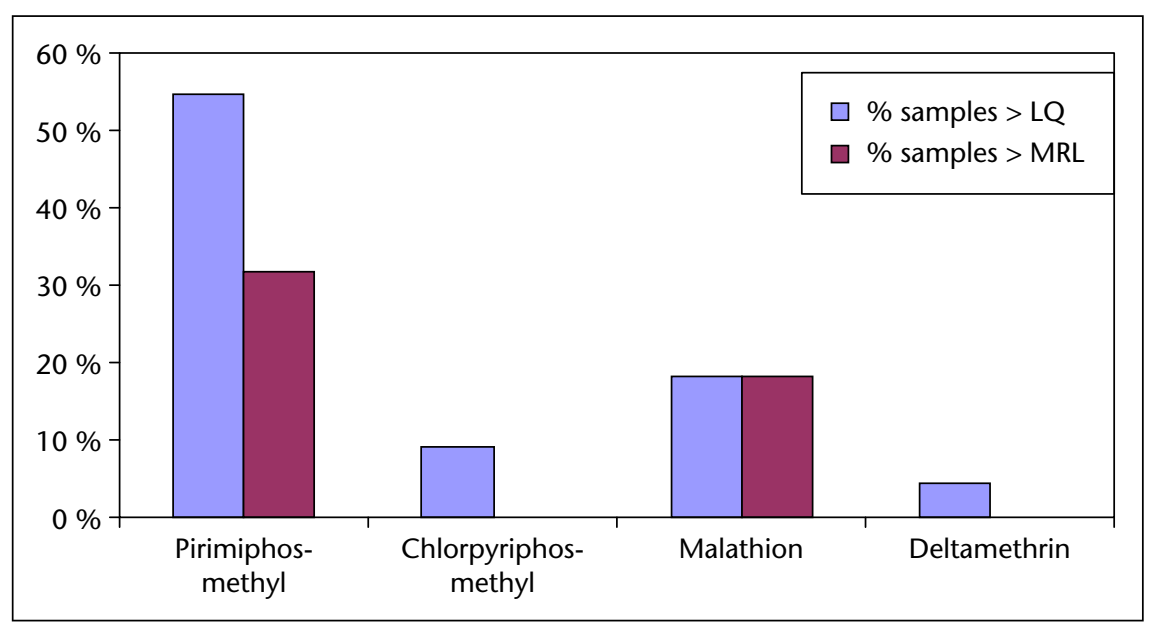

Figure 1. Statistical results on rapeseed final samples.

Table 1. Analytical results (expressed in $\mu \mathrm{g} / \mathrm{kg}$ ) on the 22 final samples of rapeseed.

\begin{tabular}{|lcrrrrrrrr|}
\hline & LQ & MRL & Mean & Median & $\begin{array}{l}\text { Standard } \\
\text { deviation }\end{array}$ & $9^{\text {th }}$ decile & Maxi & \% samples $\geq$ LQ & \% samples $>$ MRL \\
\hline Pirimiphos-methyl & 10 & 50 & 130 & 22 & 266 & 335 & 1117 & $55 \%$ & $32 \%$ \\
Malathion & 10 & - & 19 & 0 & 69 & 16 & 322 & $18 \%$ & $18 \%$ \\
Chlorpyriphos-methyl & 10 & 50 & 3 & 0 & 9 & 0 & 31 & $9 \%$ & $0 \%$ \\
Deltamethrin & 10 & 100 & 1 & 0 & 3 & 0 & 13 & $5 \%$ & $0 \%$ \\
Sum of residues & & & 152 & 34 & 290 & 581 & 1161 & & \\
\hline
\end{tabular}

LQ: limit of quantification; MRL: maximum residues limits in rapeseed; Sum of residues: $0 \mu \mathrm{g} / \mathrm{kg}$ if under the limit of quantification. 
Table 2. Analytical results (expressed in $\mu \mathrm{g} / \mathrm{kg}$ ) on the 28 final samples of sunflower seeds (previous investigation).

\begin{tabular}{|lccccccrrrr|}
\hline & LQ & MRL & Mean & Median & $\begin{array}{l}\text { Standard } \\
\text { deviation }\end{array}$ & $\begin{array}{l}\mathbf{9}^{\text {th }} \\
\text { decile }\end{array}$ & Maxi & $\begin{array}{l}\text { \% } \\
\text { samples } \geq \text { LD }\end{array}$ & $\begin{array}{l}\text { \% } \\
\text { samples } \geq \text { LQ }\end{array}$ & $\begin{array}{l}\text { \% } \\
\text { samples }>\text { MRL }\end{array}$ \\
\hline Dichlorvos & 10 & 10 & 21 & 0 & 79 & 27 & 422 & $32 \%$ & $29 \%$ & $21 \%$ \\
Pirimiphos-methyl & 10 & 50 & 19 & 5 & 55 & 29 & 295 & $61 \%$ & $39 \%$ & $4 \%$ \\
Chlorpyriphos-methyl & 10 & 50 & 0 & 0 & & & 10 & $4 \%$ & $4 \%$ & $0 \%$ \\
Malathion & 10 & - & 8 & 0 & 25 & 17 & 125 & $18 \%$ & $18 \%$ & $18 \%$ \\
Sum of residues & & & 48 & 12 & 102 & 120 & 427 & & & \\
\hline
\end{tabular}

LQ: limit of quantification; LD: limit of detection; MRL: maximum residues limits in sunflower seeds.

Sum of residues: a value of $5 \mu \mathrm{g} / \mathrm{kg}$ is given when a substance is detected but below the limit of quantification, and zero value if under the limit of detection.

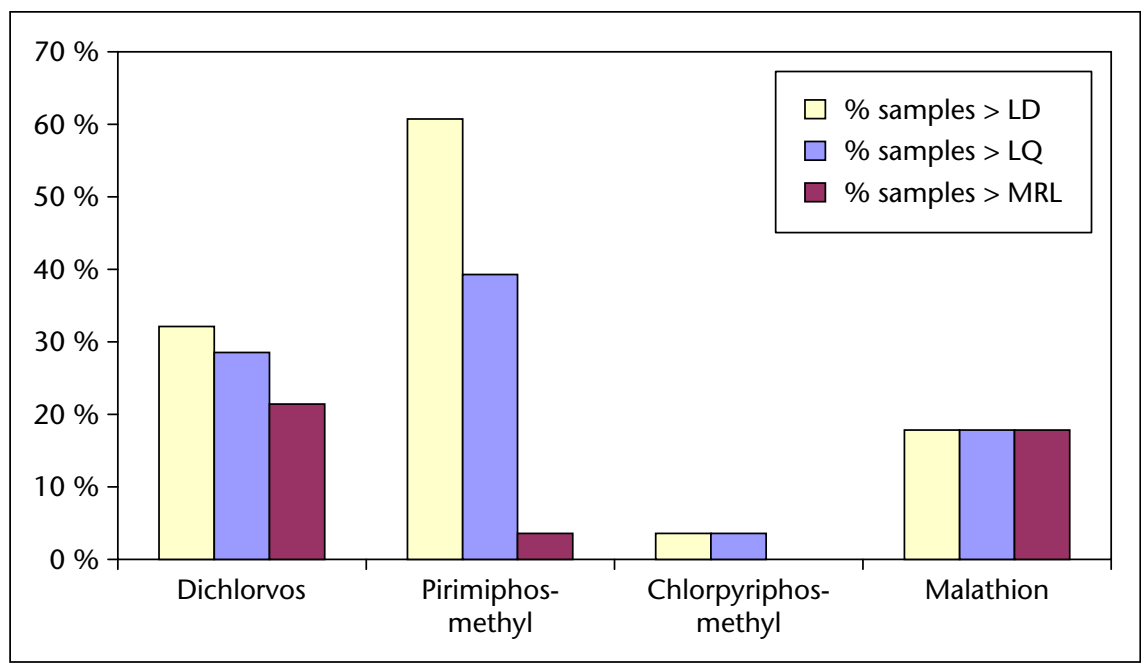

Figure 2. Statistical results on the 28 final samples of sunflower (previous investigation).

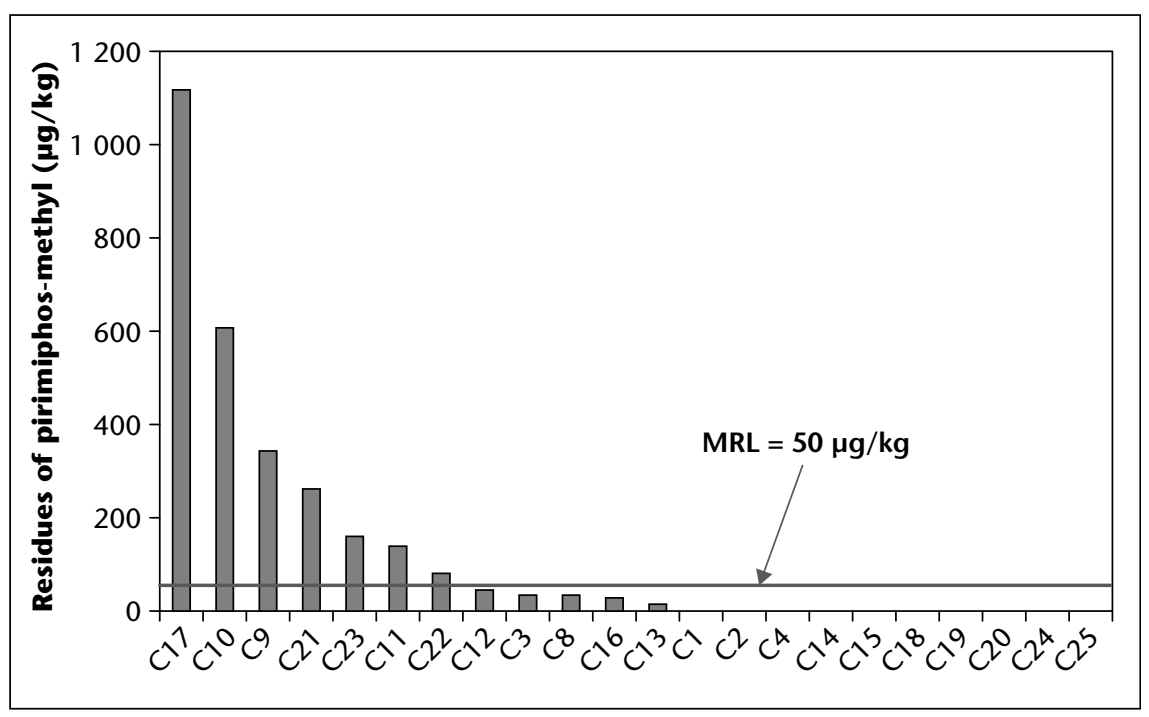

Figure 3. Individual analytical results for pirimiphos-methyl on rapeseed.

50 and $100 \mu \mathrm{g} / \mathrm{kg}$ and two samples (C16 et C17) between 10 and $20 \mu \mathrm{g} / \mathrm{kg}$. Malathion was not detected in every other sample.
Chlorpyriphos-methyl - Only two samples (C17, C21) contain chlorpyriphos-methyl at $31 \mu \mathrm{g} /$ $\mathrm{kg}$ in both, which is below the MRL $(50 \mu \mathrm{g} / \mathrm{kg})$.
Deltamethrin - Only one sample contain deltamethrin (C12) with a very low content near quantification limit $13 \mu \mathrm{g} / \mathrm{kg}$ (MRL on rapeseed for deltamethrin $=100 \mu \mathrm{g} / \mathrm{kg}$ ).

\section{Comparison with previous results on sunflower seeds}

Figure 5 and tables 1-2 show that results obtained on rapeseed harvested in 2007 are different from those obtained during the previous investigation on sunflower seeds harvested in 2006. Pirimiphos-methyl is more frequently quantified in rapeseed than in sunflower seeds (55\% for rapeseed, 39\% for sunflower seeds). And pirimiphos-methyl contents in rapeseed are higher than in sunflower seeds (means and medians: 130 and $22 \mu \mathrm{g} / \mathrm{kg}$ for rapeseed, 19 and $5 \mu \mathrm{g} / \mathrm{kg}$ for sunflower seeds. It can be explained by two reasons: since dichlorvos was prohibited, storage companies resort more frequently to preventive treatments directly on cereals with pirimiphos-methyl; also crosscontamination hazard may be higher for rapeseed since it is harvested almost at the same time that cereals (June-July).

For malathion, there is few difference between rapeseed and sunflower, in frequency and levels (table 1 and 2).

\section{Traceability analysis}

Four cases leading to cross-contamination were identified:

- K1: treatment of cereals at outloading, just before outloading of oilseeds;

- K2: outloading of cereals, treated at their receipt, just before outloading of oilseeds;

- K3: storage of treated cereals in the same bin just before storage of oilseeds;

- K4: treatment of empty bin and of handling equipment before receiving oilseeds;

- K5: receipt of oilseeds at the same time that cereals treated at receipt (concerns only rapeseed).

It appears that the biggest crosscontamination on rapeseed occurred with the 


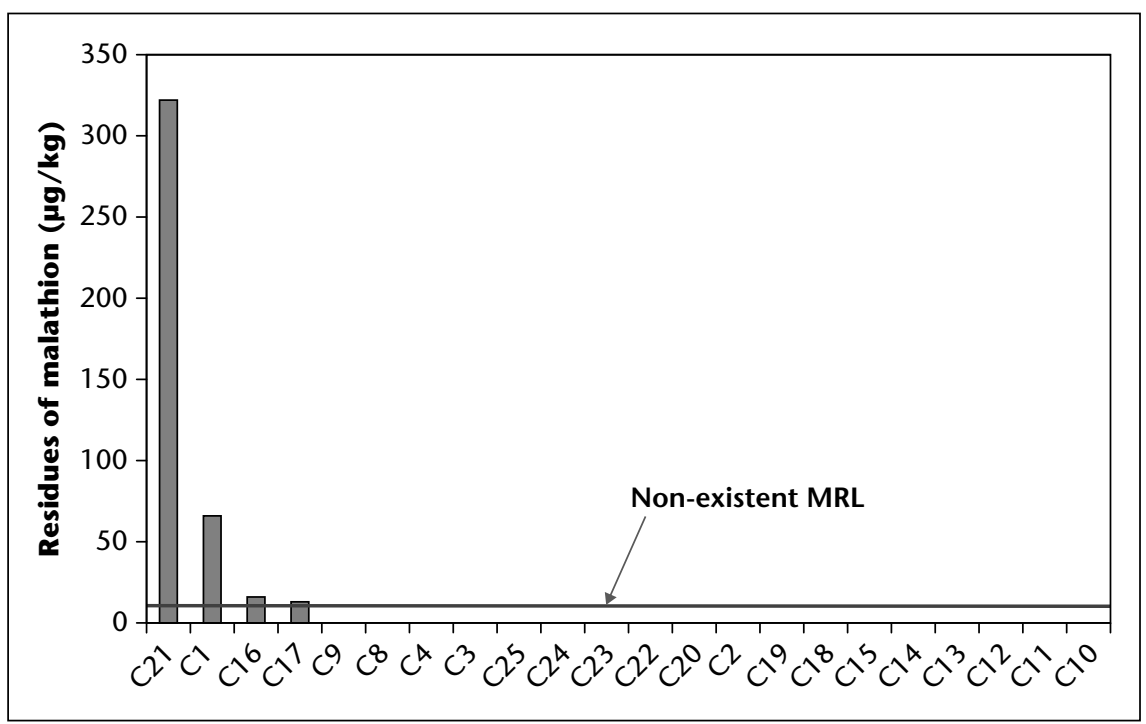

Figure 4. Individual analytical results for malathion on rapeseed.

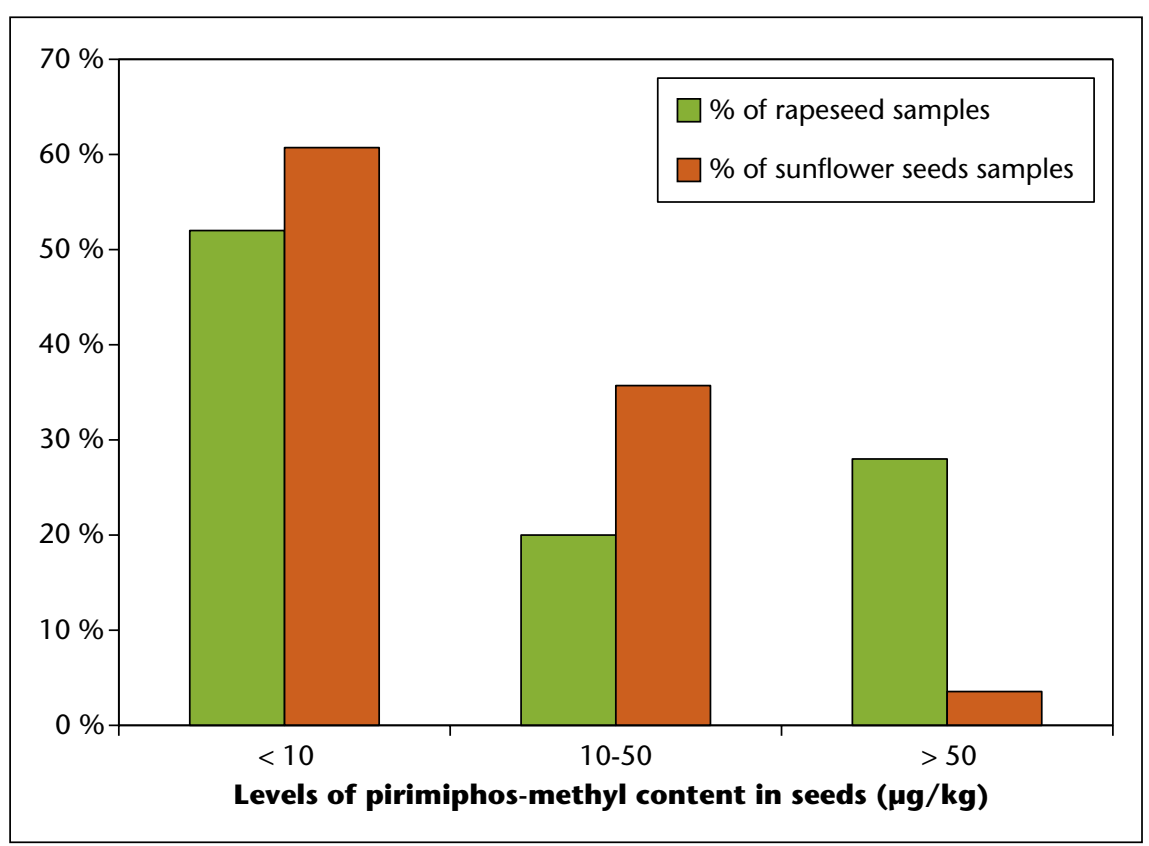

Figure 5. Comparison of pirimiphos-methyl between results on rapeseed harvested in 2007 and investigation on sunflower seeds harvested in 2006.

situation K5 (figure 6). This one is characteristic of rapeseed, which is harvested during the same period than cereals (wheat, barley) in June-July. Most samples with pirimiphosmethyl above MRL are in the situation K5. Looking at each sample, we can observe that highest contaminations occur when treatments on cereals at receipt are systematic. Treatments of cereals at receipt increased during this campaign because dichlorvos was banned. Indeed dichlorvos could be used tions with deltamethrin are slight for the time being, either because it is used since a few time, either because quantities applied are low.

$\mathrm{K} 5$ can also be linked to problem on insecticide application equipment: weak escape in the treatment system, treatment not stopped after cereals going on treating the empty circuit (accumulation of substance), mistake possible with treatment directly on rapeseed received just after cereals. These problems could not be checked in our investigation.

The situation $\mathrm{K} 1$ is less frequent than the situation $\mathrm{K} 5$, but can also lead to crosscontaminations $(\mathrm{C} 21, \mathrm{C} 3)$. It was this situation, in the previous investigation on sunflower, that led to the highest contaminations. It can also occur on rapeseed. In the case C21, malathion and chlorpyriphos-methyl were not used during the storage campaign 2007-2008, but during previous campaigns. This silo is made of concrete; so we can guess that this material can keep residues more than a year.

The case K2 can also lead to slighter crosscontaminations. The cases $\mathrm{K} 3$ and $\mathrm{K} 4$ do not cause problems, except if there are associated to other risky situations.

\section{Conclusion}

Our study in real situations showed that crosscontaminations of oilseeds by post-harvest insecticide residues exist, and can sometimes lead to residues above the regulatory limits. The highest risk of contamination for rapeseed appears when cereals are systematically treated at receipt, at the same time than rapeseed receipt, using the same conveyer circuits. The other identified cases can also lead to slighter contamination. But, silo operators have to concentrate on accumulation of several risky cases, which can worsen the contamination. Other sources of insecticide residues can occur in storage facilities, but we couldn't check them in this investigation. This include leak of insecticide by the application equipment.

We noticed differences in cross-contaminations between sunflower and rapeseed, especially because of the harvest period. But also this new investigation was carried out in the new regulatory context in which dichlorvos and malathion are forbidden for cereal treatment. Thus storage operators have new grain protection strategies, with more preventive strategies to protect cereals against pests.

So in order to reduce these cross-contaminations, we can advise to avoid sharing same reception circuits when cereals are systematically treated, and to avoid accumulation of risky situations. It is also very important to check the insecticide treatment equipment. This investigation allowed us to make the storage companies aware of this issue, and to help 


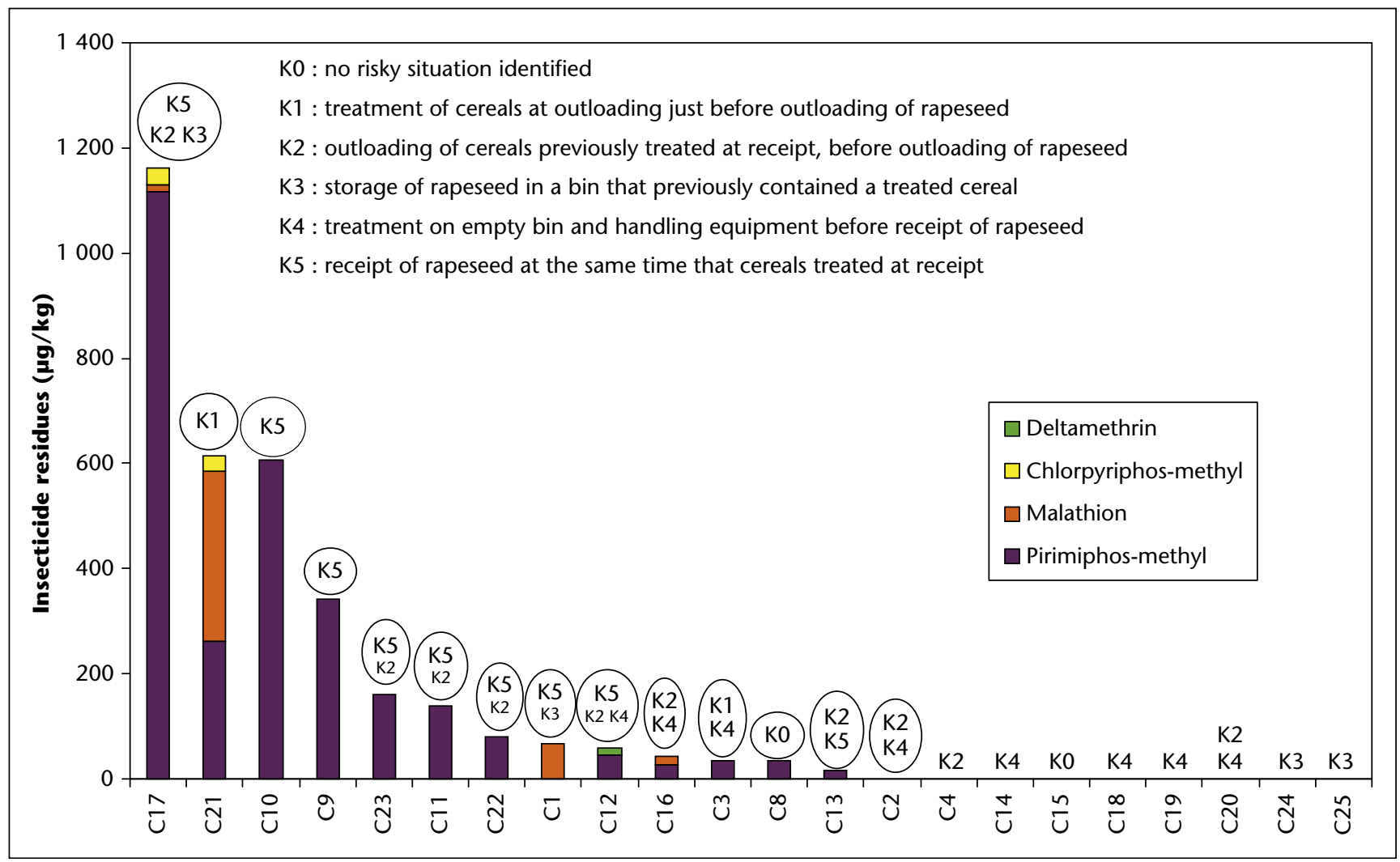

Figure 6. Distribution of the five cases $(K 1, K 2, K 3, K 4, K 5)$ for each rapeseed lot, and sum of insecticide residues $(\mu \mathrm{g} / \mathrm{kg})$ for each rapeseed final sample.

them to understand how cross-contaminations can occur in their silos and how to avoid them, knowing that each silo is different from the others.

This work was granted by ONIDOL (french oilseed chain organization) and FEDIOL (European oil and protein meal industry federation), with additional technical support of FNCG (French national oil industry federation), ITERG (French technical institute for oil industry), FNA (Fédération du Négoce Agricole), Coop de France-Métiers du grain, SAIPOL and CARGILL.

\section{REFERENCES}

1. Watters FL, Nowicki TW. Uptake of bromophos by stored rapeseed. J Econom Entomol 1982; $75: 261-4$.

2. White NDG, Nowicki TW, Watters FL. Comparison of fenitrothion and malathion for treatment of plywood and galvanized steel surfaces for control of the red flour beetle and the rusty grain beetle. I Econon Entomol 1983 ; $76: 856-63$.

3. White NDG, Nowicki TW. Effects of temperature and duration of storage on the degradation of malathion residues in dry rapeseed. / Stored Prod Res 1985 ; 21 : 111-4.
4. Dauguet $S$, Lacoste $F$, Ticot $B$, et al. La filière oléagineuse se mobilise autour de la problématique des résidus d'insecticides. OCL $2006 ; 13$ : 373-7.

5. Dauguet S, Evrard J, Fritsch J, Loison JP. Accumulation of pesticide residues in oil during the storage of rapeseed. In: $12^{\text {th }}$ International Rapeseed Congress, Wuhan Hubei, China. March 2630, 2007.

6. Dauguet $S$. Insecticide residues crosscontamination of oilseeds during storage. $\mathrm{OCL}$ $2007 ; 14: 313-6$. 